\title{
Development of an Applied Model of Metabolic Energy Delivery from 3 Mechanisms
}

\author{
Emma Swanwick* and Martyn Matthews \\ School of Health Sciences, University of Salford, UK
}

Received: June 04, 2018; Published: June 13, 2018

*Corresponding author: Emma Swanwick, School of Health Sciences, University of Salford, Frederick Road, Salford M6 6PU, UK

\section{Abstract}

The use of the three-energy system model has not been challenged since it was first demonstrated in 1963 [1]. The use of "Aerobic/ Anaerobic" terminology has become synonymous with analysis of physical work in athletic performances for many years. At the turn of the millennium the balance of the two mechanisms was further consolidated by researchers looking at athletic events [2]. This has led to the use of blood lactate to assess fitness and has been used for decades.

\section{Introduction}

Generally this is carried out at sub maximal efforts looking to identify the 4.mmol/l point [3] lactate threshold [4] OBLA [5] max lactate steady state [6] or other similar descriptive points. Although values are often recorded in competition environments, particularly in swimming, far less is written about the maximal levels of lactate achieved in competition or in maximal efforts. Lactate is the end product of the anaerobic metabolism of glucose, and its accumulation in the blood signals an increase in production or a decrease in utilization, or both $[7,8]$. It may represent the amount of anaerobic work carried out by the working muscles (fibres). Lactate may be a marker of a deficit in aerobic ATP during prolonged sustained workloads as well as accumulating as part of anaerobic glycolysis at higher intensities [9]. The use of blood lactate to monitor and predict performance has fallen out of favour since the millennium [10]. As maximal efforts extend in duration from a few seconds to minutes, there is a track-able trend of peak blood lactate dropping as the time course increases from 45 seconds onward [11]. Longer time courses show reduced lactate values around $4 \mathrm{mmol} / \mathrm{l}$ for 30 minutes of work (this is in trained athletes and can be much less time in unfit athletes). This continues to reduce as the duration of exercise extends up to and beyond 1 hour [12].

Peak lactates in swimmers has also been seen to differ due to the length of the pool [13]. Long course, 50m lengths (LC) (200m swim, $132.3 \pm 9.1 \mathrm{sec})$ and short course, or $25 \mathrm{~m}$ (SC)swimming $(200 \mathrm{~m}$ swim $128.4 \pm 10.7 \mathrm{sec}$ ), showed differences in peak lactate - (SC peak lactate of $9.27 \pm 3.1 \mathrm{mmol} / \mathrm{l}$; LC peak lactates of $10.76 \pm 3.1 \mathrm{mmol} / \mathrm{l}$ ) [13]. Post-race, peak blood lactate has also been seen to be as high as $25.7 \mathrm{mmo} / \mathrm{l}$ for 200 yards individual medley swims (where all four strokes are swum together) in USA Collegiate meets. When the 4 strokes are swum individually, over the same distance, peak blood lactates have been recorded as being between 16.4 and $20.6 \mathrm{mmol} / \mathrm{l}$ [14]. The peak blood lactate ranges for longer events were between $15.6 \mathrm{mmol} / \mathrm{l}$ for $500 \mathrm{yd}$ freestyle and $10.0 \mathrm{mmol} / \mathrm{l}$ for 1000 yards. Our own observations of competition swimming of individual male swimmers has shown values ranging from $6.1 \mathrm{mmol} / \mathrm{l}, 12.4 \mathrm{mmol} / \mathrm{l}$, $14.3 \mathrm{mmol} / \mathrm{l}, 16.2 \mathrm{mmol} / \mathrm{l}$, and $16.7 \mathrm{mmol} / \mathrm{l}$ for $1500 \mathrm{~m}$ free, $800 \mathrm{~m}$ free, $400 \mathrm{~m} \mathrm{IM}, 200 \mathrm{~m}$ free, and $100 \mathrm{~m}$ free respectively. A summary of competition mean values are summarized in Table 1 .

Table 1: Mean \& standard deviation for Mass, Time \& Blood lactate, across the swimming events during competition $(n=455)$. Blood lactate at Maximal Oxygen Uptakes (MVO2) is assumed to be greater than $8 \mathrm{mmol} / \mathrm{l}[10,15,16]$. Where an athlete shows significant anaerobic development, the level of maximal lactate is likely to be higher than this assumed peak Aerobic value. For this reason, the assumption of where MVO2 will occur in terms of lactate concentration may be misleading. There is a need to be able to identify MVO2 without the use of respiratory equipment in competitive situations. Being able to achieve this is the first aim of this experiment. We have previously shown that at maximal effort, blood glucose also follows a time course response [17]. As the duration of effort gets longer from 45 seconds onwards, the blood glucose rises. It appears to peak between 8 and 16 minutes before then reducing again toward resting values and below. Although the effect of endurance work on blood glucose is well documented [6,18-20] the 
increase in blood glucose in this maximal effort situation is due to two elements:- the increased output by the liver and kidneys, and the inability of the working muscle fibres to take up the increased amount of circulating glucose in the blood [18]. The latter itself is a marker of an increase in the use of muscle glycogen and may also mark the recruitment of type 2a muscle fibres [21].

Previously we have challenged that the model of " 3 energy systems" (creatine phosephate, anaerobic and aerobic) is in fact not detailed enough and can lead to miss-understanding of what is being classed as "Aerobic" work [17]. By doing so, it can and does lead to inappropriate exercise prescription. By defining a new timeline for energy mechanisms to work to, that recognizes and includes the importance of the Malate Aspartate lactate shuttle, a better understanding of energy metabolism can be created. We proposed that it is possible to use the maximum lactate from an effort and predict at what level of blood lactate MVO2 occurred. We would use this to identify the point from which anaerobic capacity could be defined. Additionally, using the change in blood glucose, we proposed that it could be used to identify the amount of work that was met by aerobic glycolytic mechanisms. From the combination of these two, we could then define the different aerobic contributions along with the anaerobic contributions within a maximal effort.

\section{Methods \\ Subjects}

Ten national or international-standard male swimmers participated in the study. The swimmers (age $20.6 \pm 2.04$ years; body mass $85 \pm 4 \mathrm{Kg}$; \% body fat $9.4 \pm 0.01$ ) all followed a similar program of training, involving 8-10 sessions of pool training per week. Training consisted of a mixture of low, moderate, and maximal intensity aerobic work, short sprints, and pool-based, stroke-specific drills and exercises. Weekly swimming training volume averaged $54 \pm 19 \mathrm{~km}$. All swimmers also carried out land-based resistance training, and flexibility work 3-5 times per week.

\section{Experimental Design}

The swimmers underwent the following protocol. A $200 \mathrm{~m}$ swim at close to the maximum race pace was swum from a push start. During this swim, split times were taken at $50 \mathrm{~m}, 100 \mathrm{~m}$ and $150 \mathrm{~m}$. Following a 30 -minute active and passive recovery, each swimmer then swam the split time for the $1 \mathrm{st} 50 \mathrm{~m}$ of the $200 \mathrm{~m}$, then the $100 \mathrm{~m}$-split time, and finally the $150 \mathrm{~m}$ split time. Each swim was broken with the 30-minute active and passive recovery period. Before each of the split swims, the recovery lactate had to be within $1 \mathrm{mmol} / \mathrm{l}$ of the initial resting lactate prior to the start of the 200 swim.

\section{Data Collection}

All swims were carried out in a $50 \mathrm{~m}$ pool and water was at 27.5 0C throughout all experiments. Following the end of each swim, swimmers breathed through a respiratory mask and expired gas was collected for 2 minutes. During this period $25 \mu \mathrm{l}$ of blood was excised from the earlobe 1,3,5,7 and, if necessary, 9 minutes post swim, until a peak was reached in both blood lactate and blood glucose. Blood lactate and blood glucose were measured using a YSI
1500, (Yellow springs, OHIO, USA). Heart rate was also recorded immediately on completion of each swim using a polar vantage monitoring system (Polar,Electro Oy, Kempele, Finland) looking for the peak heart rate. Times were recorded in seconds to the nearest 10 th of a second.

Calculation of MVO2 and the percentage contribution of the three components:

The model for the calculation of the three components: aerobic; glycolytic; and anaerobic contributions are as follows;

Lactate at MVO2 “a” $=(0.4571 *$ maximum lactate $)+3.3524$

Now that we have the point at which MVO2 occurs, all work done above this point is therefore anaerobic by nature (either anaerobic glycolysis or CP-ATP derived). Anaerobic Contribution as a percentage was defined as:

$$
((\text { max lactate } /((0.4571 * \text { max lactate })+3.3524)) * 100)-100)
$$

The calculation of aerobic glycolysis requires us to use the changes in blood glucose from post warm up, pre-maximum effort (not rest necessarily). The glycolytic contribution will be equal to the shift in glucose from the state prior to the maximum effort. Aerobic glycolysis was calculated as:

$$
\text { Glyc } \max \text { "g" }=100-((\max \text { glucose / resting glucose })) * 100
$$

The aerobic oxidative contribution is then assumed to be that which is not included in the degree of blood glucose change or that which contributes to the increase in blood lactate also. The aerobic percentage is therefore defined as:

$$
\text { Aerobic } \max =(100-(a+g))
$$

Where the total $=100 \%$.

With the calculated values, the aim was to construct a model that could be used to assess an athlete's mechanism contribution during maximal efforts. This tri-phasic model would be demonstrated through a triangle chart to demonstrate the direction of each components percentage contribution. To test out the accuracy of calculation of lactate at MVO2 we used the data from the maximal $200 \mathrm{~m}$ swims. The values measured through the backward extrapolated MVO2 were then compared to the MVO2 Calculated from the maximal lactate.

\section{Statistics}

All values are given as mean \pm SD. Regression tests studied the relationship between the measured and the predicted MVO2. A one-way ANOVA was used to analyse differences between contributions of the maximal $200 \mathrm{~m}$ swim. $95 \%$ confidence limits were set. The AIS research ethics board approved this study. All participants provided both verbal and written confirmation of their consent to participate in the study. The study also adhered to the ethical standards of the Australian sports commission.

\section{Results}

Mean 200m swimming time and mean splits for each 50 are shown in Table 1: Mean splits and overall swim time. Mean MVO2 
for the group was $3.94 \pm 0.27 \mathrm{~L} / \mathrm{min}$. Mean maximal lactate at the end of the $200 \mathrm{~m}$ swim was $13.92 \pm 3.19 \mathrm{mmol} / \mathrm{l}$. Mean lactate at MVO2 both measured and predicted are shown in Table 2: mean of the measured and predicted MVO2. The relationships between the measured and predicted values are also shown in Figure 1: Re- lationship between predicted and measured lactate at maximum oxygen uptake. There was no difference between the measured and predicted lactate and the regression equation showed good a good fit $(\mathrm{r} 2=0.92 \mathrm{P}=0.30)$.

Table 1: Mean \& standard deviation for Mass, Time \& Blood lactate, across the swimming events during competition ( $\mathrm{n}=455)$.

\begin{tabular}{|c|c|c|c|c|c|c|c|c|}
\hline Event & Gender & $\neq$ & Mass(Kg) & \pm & Time (sec) & \pm & Lact(mmol/l) & \pm \\
\hline \multirow{2}{*}{1500 free } & Female & 4 & 55 & 1.23 & 1045.94 & 28.43 & 3.5 & 0.2 \\
\hline & male & 9 & 76.44 & 3.71 & 961.08 & 67.43 & 6.39 & 2.5 \\
\hline \multirow{2}{*}{800 free } & Female & 4 & 57.75 & 2.06 & 542.62 & 9.14 & 8.98 & 2.4 \\
\hline & male & 3 & 79.4 & 6.3 & 496.53 & 7.39 & 10.1 & 2.3 \\
\hline \multirow{2}{*}{$400 \mathrm{IM}$} & Female & 10 & 60.8 & 4.21 & 287.61 & 18.22 & 8.96 & 2.35 \\
\hline & male & 4 & 76 & 3.26 & 249.6 & 7.53 & 11.3 & 3.1 \\
\hline \multirow{2}{*}{$200 \mathrm{IM}$} & Female & 13 & 60.23 & 3.47 & 145.78 & 3.93 & 11.1 & 2.51 \\
\hline & male & 5 & 79 & 12.63 & 129.48 & 6.48 & 12.64 & 2.08 \\
\hline \multirow{2}{*}{200 free } & Female & 8 & 57.13 & 6.1 & 130.37 & 6.25 & 11.54 & 1.15 \\
\hline & male & 44 & 79.91 & 4.87 & 116.63 & 7.18 & 13.05 & 2.3 \\
\hline \multirow{2}{*}{200 fly } & Female & 10 & 60 & 4.27 & 158.11 & 11.12 & 10.2 & 1.81 \\
\hline & male & 34 & 77.35 & 4.84 & 129.45 & 11.78 & 12.69 & 4.72 \\
\hline \multirow{2}{*}{200 breast } & Female & 9 & 66.11 & 6.92 & 167.7 & 11.03 & 10.5 & 2.42 \\
\hline & male & 29 & 76.48 & 5.4 & 146.79 & 21.68 & 11.3 & 2.63 \\
\hline \multirow{2}{*}{200 back } & Female & 13 & 65.92 & 6.54 & 140.5 & 6.94 & 13.15 & 1.88 \\
\hline & male & 6 & 76 & 9.08 & 126.63 & 1.35 & 12.27 & 2.87 \\
\hline \multirow{2}{*}{100 back } & Female & 4 & 59.5 & 4.43 & 68.53 & 5.15 & 15.85 & 6.82 \\
\hline & male & 10 & 79.2 & 7.39 & 64.06 & 6.74 & 11.38 & 2.72 \\
\hline \multirow{2}{*}{100 breast } & Female & 18 & 64.28 & 10.46 & 73.92 & 4.82 & 9.3 & 2.28 \\
\hline & male & 19 & 80.26 & 3.36 & 65.62 & 3.58 & 11.79 & 2.56 \\
\hline \multirow{2}{*}{$100 \mathrm{fly}$} & Female & 16 & 69.15 & 10.82 & 71.02 & 15.16 & 9.54 & 2.48 \\
\hline & male & 20 & 79 & 7.44 & 67.42 & 25.38 & 11.95 & 2.98 \\
\hline \multirow{2}{*}{100 free } & Female & 13 & 58.69 & 4.89 & 61.35 & 2.67 & 11.52 & 1.84 \\
\hline & male & 109 & 82.12 & 6.55 & 51.36 & 3.37 & 13.74 & 2.96 \\
\hline \multirow{2}{*}{50 free } & Female & 11 & 67.73 & 9.82 & 27.66 & 1.41 & 10.7 & 1.12 \\
\hline & male & 20 & 87.4 & 5.2 & 22.76 & 0.33 & 12.62 & 1.63 \\
\hline \multirow{2}{*}{50 fly/ back } & Female & & & & & & & \\
\hline & male & 10 & 18.8 & 1.87 & 26.75 & 2.22 & 9.59 & 2.14 \\
\hline
\end{tabular}

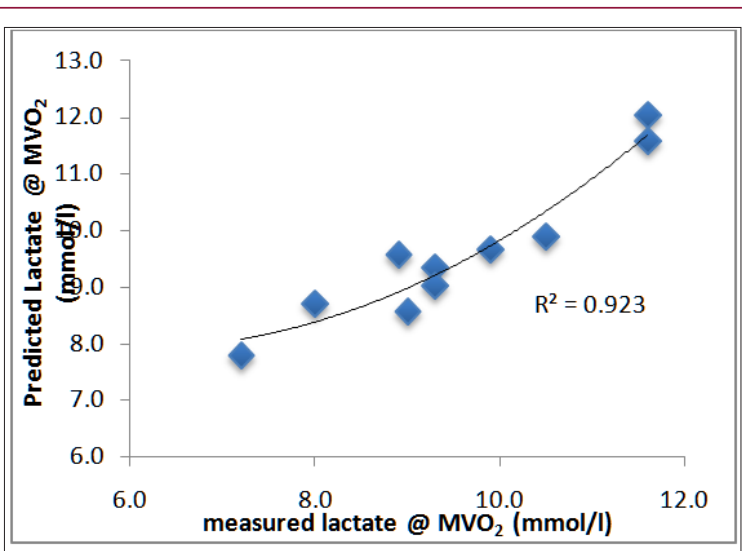

Figure 1: Relationship between predicted and measured lactate at maximum oxygen uptake.
Table 2: Mean splits and overall swim time.

\begin{tabular}{|c|c|c|c|c|}
\hline Distance & $\begin{array}{c}\text { Mean Spilt } \\
\text { (sec) }\end{array}$ & St Dev & $\begin{array}{c}\text { Mean 50 } \\
\text { time (sec) }\end{array}$ & St Dev \\
\hline 50 & 28.20 & 0.57 & 28.20 & 0.57 \\
\hline 100 & 57.72 & 1.12 & 29.52 & 0.85 \\
\hline 150 & 87.48 & 1.66 & 29.76 & 0.93 \\
\hline 200 & 117.76 & 2.35 & 30.28 & 0.88 \\
\hline
\end{tabular}

Using this predictability of lactate at $\mathrm{MVO} 2$, this was then used in the calculation of anaerobic contribution as detailed above. The relationship of the origin of energy and the maximal lactate and glucose readings during the maximal swim of the 10 swimmers are shown in Table 3. (Figure 2) The mean contribution values for this $200 \mathrm{~m}$ swim were; aerobic $36.41 \pm 15.19 \%$, Glycolytic $22.07 \pm$ $10.01 \%$ and anaerobic $41.52 \pm 10.34 \%$. 
Figure 2: Mean percentage mechanisms used in a $200 \mathrm{~m}$ time trial $(\mathrm{N}=10)$. Table 3: Lactate, Glucose maximum values for each swimmer and the relative contribution of energy pathways (\%). Individual variation of how the demand of maximally swimming the $200 \mathrm{~m}$ can be seen. As a demonstration of how the profile can be displayed, three examples of how the profile individually differed are shown in Figure 3 is the desired profile for a 200m event. Figure 3: Examples of profiles for 3 different swimmers tested at the same time. When the individuals' profiles were compared to the optimal values predicted for the $200 \mathrm{~m}$ swim in the mean time of 1 minute $57.76 \mathrm{sec}$ ( $\mathrm{SD} \pm 2.35 \mathrm{sec}$ ) only 3 swimmers had an R2 above 0.90 . All other swimmers in the group reported RSQ below 0.26 . The regression values are shown in Table 3.

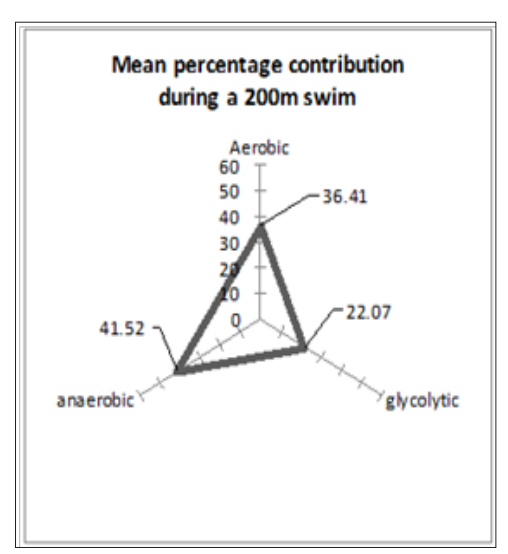

Figure 2: Mean percentage mechanisms used in a $200 \mathrm{~m}$ time trial $(\mathrm{N}=10)$.

Table 3: Mean of the measured and predicted $\mathrm{MVO}_{2}$.

\begin{tabular}{|c|c|c|}
\hline MVO $_{2}$ : Subjects =10 & Measured & Pred Vo2 \\
\hline Mean & 9.53 & 9.61 \\
\hline Standard Error & 0.45 & 0.42 \\
\hline Standard Deviation & 1.42 & 1.31 \\
\hline Sample Variance & 2.02 & 1.72 \\
\hline $\begin{array}{c}\text { Confidence Level } \\
(95.0 \%)\end{array}$ & 1.02 & 0.94 \\
\hline
\end{tabular}

\section{Discussion}

Swimmers in the same race do not necessarily meet the demands of that race in the same way. This will depend upon their individual level of "Fitness" and the relative effort made during the race. Blood lactates vary in maximal swims and the peak lactates reported here do not necessarily agree with those seen in other studies on swimmers $[13,14]$. What is evident is that lactate concentrations in the blood appear to peak in the $100 \& 200 \mathrm{~m}$ events (between 45 and 120 seconds in duration) and then the mean peak of lactate drops as the time taken to swim an event increases. Using the formula proposed, the production of a reliable measure of the lactate at MVO2 has been achieved. The mean predicted blood lactate at MVO2 of $9.61 \mathrm{mmol} / \mathrm{l}$ was above that originally suggested by previous authors [15,22-24]. This may still represent a sub-maximal exercise intensity in individuals capable of accumulating blood lactate concentrations of $15 \mathrm{mmol} / \mathrm{l}$ or more.
Knowing the peak lactate does not allow us to suggest at which point the swimmer reached or passed MVO2. We wanted to be able to identify the blood lactate concentration at which MVO2 occurred, to be able to identify the anaerobic contribution to the overall balance of energy mechanisms during a maximal effort. That is, all energy produced above MVO2 must be anaerobic. This can fit with the definition provided by Green \& Dawson [25] who suggested that in such events as the $800 \mathrm{~m}$ run or $1000 \mathrm{~m}$ cycle, to be able to recommend training appropriately it was important to accurately measure the anaerobic capacity as it was representative of the ATP resythesis through anaerobic metabolism in such short term maximal exercise. This time line also fits events such as the $100 \mathrm{~m}$ and $200 \mathrm{~m}$ swimming events used in this study. For this reason, we would suggest that the anaerobic work capacity is what has been measured by the protocol used in this study.

When the mean values of the group were considered, the anaerobic contribution for the $200 \mathrm{~m}$ swims was $41 \%$, which is slightly higher than that reported for males running 800m (39.7\%)[26] [11]. The major difference of this study to previous studies looking at energy contribution $[2,26]$, is that we split the aerobic capacity in to 2 elements, Aerobic and aerobic glycolytic. This gave a different understanding of how the aerobic metabolism was being met. Although the concept of aerobic oxidative metabolism (from fat and blood sugar) and aerobic glycolytic (from glycogen) is well documented, to our understanding, methods to split these two components has not been presented previously.

With training, plasma glucose clearance and oxidation are greatly reduced [25-29] and at intensities above $65 \%$ of MVO2, endurance training brings about little or no change in fat oxidation, although turn over does increase [30].

Further it has been noted that

a) Glucose use is directly related to exercise intensity

b) training decreases glucose flux for a given power output.

c) when expressed as relative exercise intensity, training does not affect the magnitude of blood glucose use during exercise.

d) Training alters the pathways of glucose disposal [29].

Although in relative terms blood glucose does not change, when absolute intensity changes, it does modify the blood glucose level by lowering it $[31,32]$. These are important for the identification of training improvements in athletes and represent the aerobic oxidation of plasma glucose element of the development of fitness. Hyperglycemia in trained subjects during intense exercise appears to be due to a lower rate of glucose utilization rather than a higher rate of glucose production [18] and would represent a demarcation line between aerobic oxidative metabolism and aerobic glycolytic (reliant upon muscle glycogen) metabolism. At higher intensities of exercise, glycogen stores in type $2 \mathrm{a}$ and to a greater extent in type 1 muscle fibres, both decrease [19]. Glycogen stores in type 2a and $2 x$ fibres and type 1 fibres, were depleted significantly more slowly in the trained than in the untrained individual $[33,34]$. The impor- 
tance of the glycolytic metabolism is increased when the activity of the Malate Aspartate Shuttle in aiding the retention of aerobic functionality as exercise increases above the point where readily understood mechanisms of lactate and pyruvate metabolism prevails [19]. The point at which blood glucose rises (the glucose turn point) [32] could be a demarcation point between the oxidative and glycolytic metabolism during intense exercise and fits with the model that we have proposed in other work [17]. Further, the limit of the aerobic glycolytic metabolism would be at MVO2.

Using the split of aerobic capacity in to the 2 elements of aerobic oxidative an aerobic glycolytic work, and knowing that we are in agreement with previous studies in regards to the anaerobic contribution, the split of the aerobic components becomes important to understand where differences in capability to meet aerobic demands may occur. Based on our previous work [11], where time line requirements are suggested, a model balance of pathway use was produced for the $200 \mathrm{~m}$ swims based on the mean time for the swim of 1 minute 57.79 seconds \pm 2.35 seconds. Only 3 swimmers showed responses that were within a reasonable chance of achieving the event requirements. The remainder of the group demon- strated profiles that were unlikely to meet the relative race requirements to be able to perform well over such a distance (timeline) should such a race be required at the time of testing $[33,34]$.

The three profiles shown in Figure 3 demonstrate how different individuals met the same work demand. All three swam within 1 second of each other on the $200 \mathrm{~m}$ swim $(116.29,116.88 \& 117.29$ sec) but the contribution showed almost no glycolytic contribution (swimmer 1), a predominantly aerobic contribution (swimmer 2) and a predominantly anaerobic balance (swimmer 7). All of these swimmers were in a relatively unfit state at the time of testing (swimmers had only completed 1 week of training after a 3 week lay off). These differences give a view that may be able to provide an insight as to why some athletes respond to a particular training program while others may struggle to cope with it. The relative differences in the aerobic components mark a large division in the load that would be created on each individual. A load intended to be at $85 \%$ of MVO2 would be met with equal balance from swimmer 2, could use too much anaerobic capacity by swimmer 7 but is likely to aerobically overload swimmer 1 . This is critical information if failing adaptation is to be avoided.

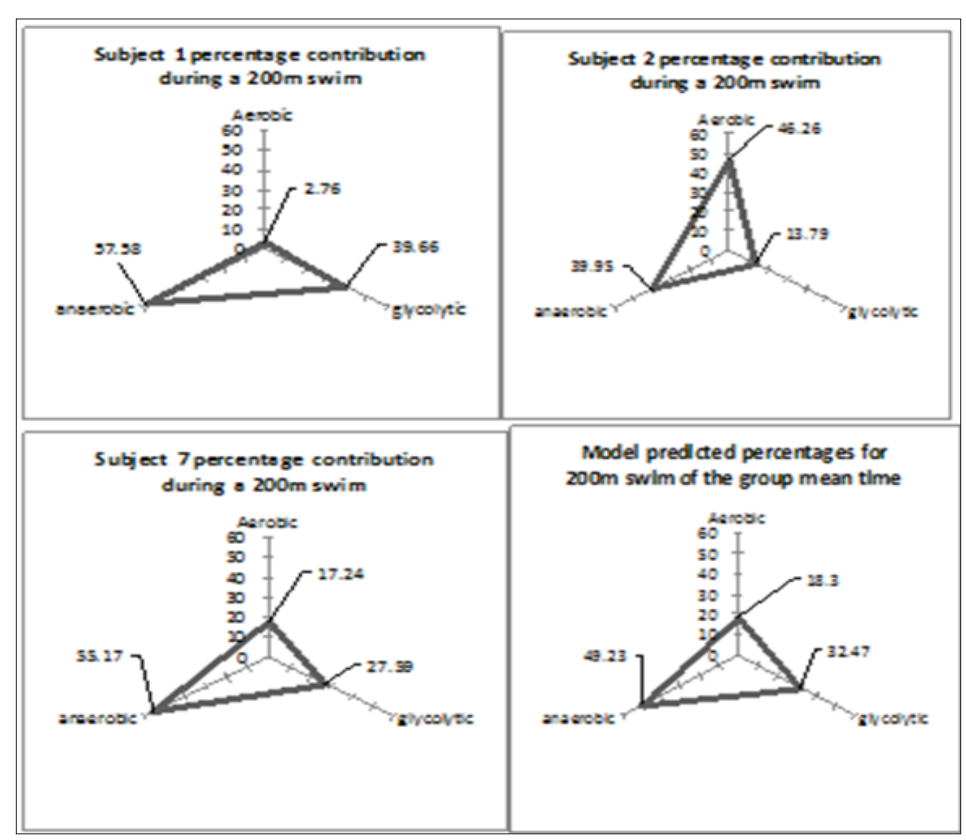

Figure 3: Examples of profiles for 3 different swimmers tested at the same time.

\section{Conclusion}

We have shown that the lactate at MVO2 can be predicted with a good reliability using a simple algorithm. This allows the identification of the anaerobic contribution during maximal swims which was similar to that obtained by previous authors using much more complex testing methods. Additionally, the redefining of the aerobic contribution into that which is oxidative and that which is glycolytic in basis for practical measurement was briefly justified and outlined. Having the ability to measure the distinction between these two components of aerobic metabolism to identify critical differences between individuals when swimming at the same rel- ative intensity provides a mechanism to enhance training intensity observation, improve exercise prescription and training adherence. This method could provide important guidance in ensuring that the prescription of exercise is more individually specific.

\section{References}

1. Değermenci M, Ertekin T, Ülger H, Acer N, Coşkun A (2016) The Age Related Development of Maxillary Sinus in Children. J Craniofac Surg 27(1): 38-44.

2. Lorkiewicz Muszyńska D, Kociemba W, Rewekant A, Sroka A, Jończyk Potoczna K, et al. (2015) Development of the maxillary sinus from birth to age 18. Postnatal growth pattern. Int J Pediatr Otorhinolaryngol 79: 1393-400. 
3. Kim J, Song SW, Cho JH, Chang KH, Jun BC (2010) Comparative study of the pneumatization of the mastoid air cells and paranasal sinuses using three-dimensional reconstruction of computed tomography scans. Surg Radiol Anat 32(6): 593-599.

4. Saccucci M, Cipriani F, Carderi S, Di Carlo G, D’Attilio M, et al. (2015) Gender assessment through three-dimensional analysis of maxillary sinuses by means of Cone Beam Computed Tomography. Eur Rev Med Pharmacol Sci 19(2): 185-193.

5. Jun BC, Song SW, Park CS, Lee DH, Cho KJ, et al. (2005) The analysis of maxillary sinus aeration according to aging process; volume assessment by 3-dimensional reconstruction by high-resolutional CT scanning. Otolaryngol Head Neck Surg 132(3): 429-434.

6. Reichs KJ (1993) Quantified comparison of frontal sinus patterns by means of computed tomography. Forensic Sci Int 61(2-3): 141-168.

7. Kondo T, Zákány J, Innis JW, Duboule D (1997) Of fingers, toes and penises. Nature 390: 29.

8. Manning JT (2002) Digit ratio: A pointer to fertility, behavior, and health. Rutgers University Press.

9. Bilgic Ö, Altınyazar HC, Eryılmaz D, Tuğrul ZA (2016) Are 2D: 4D finger-length ratios an indicator of androgenetic alopecia in males? Anaisbrasileiros de dermatologia 91(2): 156-159.

10. Meindl K, Windhager S, Wallner B, Schaefer K (2012) Second-to-fourth digit ratio and facial shape in boys: the lower the digit ratio, the more robust the face. Proc Biol Sci 279: 2457-2463.

11. Manning JT, Bundred PE, Newton DJ, Flanagan BF (2003) The second to fourth digit ratio and variation in the androgen receptor gene. Evol Hum Behav 24(6): 399-405.

12. Byne W (2006) Developmental endocrine influences on gender identity: implications for management of disorders of sex development. Mt Sinai J Med 73(7): 950-959.

13. Breedlove SM (2010) Minireview: organizational hypothesis: instances of the fingerpost. Endocrinology 151(9): 4116-4122.

14. Trivers R, Manning J, Jacobson A (2006) A longitudinal study of digit ratio (2D: 4D) and other finger ratios in Jamaican children. Horm Behav 49(2): 150-156.

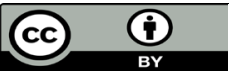

This work is licensed under Creative Commons Attribution 4.0 License

Submission Link: https://biomedres.us/submit-manuscript.php
15. Prabhat M, Rai S, Kaur M, Prabhat K, Bhatnagar P, et al. (2016) Computed tomography based forensic gender determination by measuring the size and volume of the maxillary sinuses. J Forensic Dent Sci 8(1): 40-46.

16. Weinberg SM, Parsons TE, Raffensperger ZD, Marazita ML (2015) Prenatal sex hormones, digit ratio, and face shape in adult males. Orthod Craniofac Res 18(1): 21-26.

17. Leoni B, Rubolini D, Romano M, di Giancamillo M, Saino N (2008) Avian hind-limb digit length ratios measured from radiographs are sexually dimorphic. J Anat $213:$ 425-430.

18. Möhlhenrich SC, Heussen N, Peters F, Steiner T, Hölzle F, et al. (2015) Is the Maxillary Sinus Really Suitable in Sex Determination? A ThreeDimensional Analysis of Maxillary Sinus Volume and Surface Depending on Sex and Dentition. J Craniofac Surg 26(8): 723-726.

19. Kanthem RK, Guttikonda VR, Yeluri S, Kumari G (2015) Sex determination using maxillary sinus. J Forensic Dent Sci 7(2): 163-167.

20. Fernandes CL (2004) Forensic ethnic identification of crania: The role of the maxillary sinus - A new approach. Am J Forensic Med Pathol 25(4): 302-313.

21. Sahlstrand Johnson P, Jannert M, Strömbeck A, Abul Kasim K (2011) Computed tomography measurements of different dimensions of maxillary and frontal sinuses. BMC Med Imaging 11: 8 .

22. Vidya CS, Shamasundar NM, Manjunatha B, Raichurkar K (2013) Evaluation of size and volume of maxillary sinus to determine gender by 3D computerized tomography scan method using dry skulls of South Indian origin. Int J Curr Res Rev 5(3): 97-100.

23. Attia AM, Badrawy AM, Shebel HM (2012) Gender identification from maxillary sinus using multi-detector computed tomography. Mansoura J Forensic Med Clin Toxicol 20: 17-26.

24. Uchida Y, Goto M, Katsuki T, Akiyoshi T (1998) A cadaveric study of maxillary sinüs size as an aid in bone grafting of the maxillary sinus floor. J Oral Maxillofac Surg 56(10): 1158-1163.

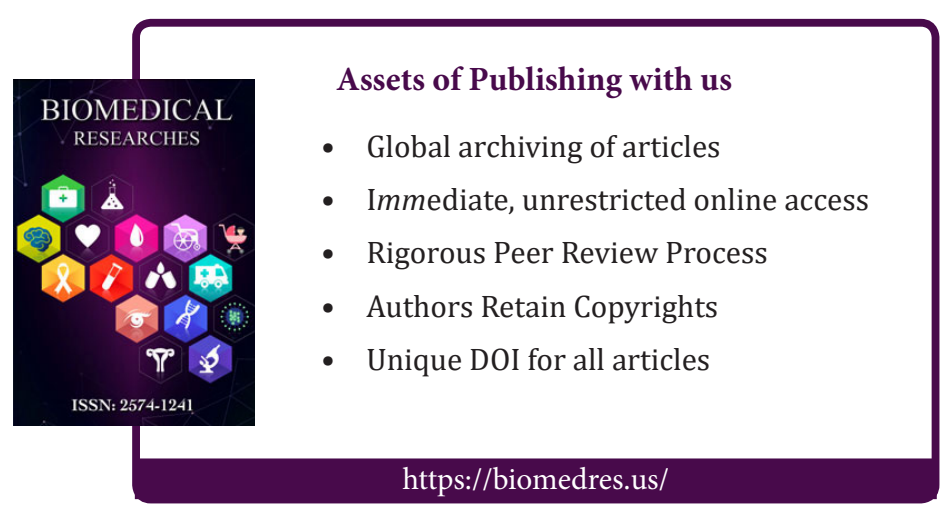

